\title{
Bioactive hydrolysates from bovine blood globulins: generation, characterization, and in silico prediction of toxicity and allergenicity
}

Tomas Lafarga ${ }^{a}$, Matthias Wilm ${ }^{\mathrm{b}}$, Kieran Wynne ${ }^{\mathrm{b}}$, and Maria Hayes ${ }^{\mathrm{a} *}$

a Teagasc, The Irish Agricultural and Food Development Authority, Food BioSciences Department, Ashtown, Dublin 15, Dublin, Ireland.

${ }^{\mathrm{b}}$ Conway Institute, University College Dublin, Belfield, Dublin 4, Ireland.

"Corresponding author: Dr. Maria Hayes | Teagasc Food Research Centre, Ashtown, Dublin 15, Dublin, Ireland | Phone: +353 (0) 18059957 | E-mail: maria.hayes@teagasc.ie

\begin{abstract}
Abbreviations: EFSA: European Food Safety Authority; ACE-I: angiotensin-I-converting enzyme; DPP-IV: dipeptidyl peptidase-IV; GIP: gastric-inhibitory peptide; GLP-1: glucagonlike peptide-1; MWCO: molecular weight cut-off; MS: mass spectrometry; LC: liquid chromatography; FA: formic acid; DMSO: dimethyl sulfoxide; ACN: acetonitrile; TCA: trichloroacetic acid; MW: molecular weight; S.D.: standard deviation; FAO: Food and Agriculture Organisation; WHO: World Health Organisation; SEM: standard error of the mean.
\end{abstract}




\begin{abstract}
Two protein fractions rich in $\gamma$-globulins (FI) and $\alpha$ - and $\beta$-globulins (FII) were generated from bovine blood and hydrolyzed with the enzyme papain. The generated hydrolysates showed in vitro angiotensin-I-converting enzyme (ACE-I), renin, and dipeptidyl peptidase-IV (DPP-IV) inhibitory activities. A total of 626 and 2246 peptides were identified by LCMS/MS from the $1 \mathrm{kDa}$ fractions of FI and FII and the potential toxicity and allergenicity of these peptides were assessed in silico using three independent predictive approaches. All of the peptides identified from the bioactive blood protein fractions FI and FII were predicted to be non-toxic. However, 72 peptides from FI and 492 peptides from FII were identified as potential allergens with at least two predictive approaches. Results suggested that papain hydrolysates of FI and FII contain potential allergenic peptides and those products containing such hydrolysates should be labeled correctly in line with Food and Consumer legislation Regulation (EU) No.1169/2011.
\end{abstract}

Keywords: bovine blood proteins, ACE-I, allergenicity, in silico analysis, functional ingredients, bioinformatics 


\section{Introduction}

Bioactive peptides are short sequences of amino acids that are inactive within the sequence of the parent protein but have positive impacts on systems of the body once released by the action of microorganisms, enzymes, or acids (Korhonen \& Pihlanto, 2006). Although blood is an excellent raw material for the generation of angiotensin-I-converting enzyme (ACE-I; EC3.4.15.1), renin (EC 3.4.23.15), and DPP-IV (DPP-IV; EC 3.4.14.5) inhibitory peptides (Bah, Bekhit, Carne, \& McConnell, 2013; Lafarga \& Hayes, 2014), few bioactive hydrolysates and peptides have been generated from bovine blood globulins to date. These included trypsin and Alcalase hydrolysates of bovine globulins which previously showed ACE-I IC 50 values of 8.14 and $7.11 \mathrm{mg} / \mathrm{mL}$, respectively (Hyun \& Shin, 2000).

Inhibition of ACE-I and renin plays a key role in the treatment of hypertension and inhibition of DPP-IV has potential for use in the treatment of type-2 diabetes, hypercholesterolemia, and insulin resistance as demonstrated in a number of studies to date (Dicker, 2011; JuilleratJeanneret, 2014). Bioactive hydrolysates and peptides generated from blood proteins show potential for use as health-promoting ingredients in functional ingredients, and the identification of novel bioactive peptides with health-promoting properties would not only provide a commercial opportunity for many companies but may also have a role in improving public health. However, although the processes used for the generation of protein hydrolysates are common in the food industry and usually use food-grade materials, processing aids, and equipment, proteins and peptides can be toxic and produce allergic reactions after ingestion (Wang \& De Mejia, 2005). Indeed, some of the most important toxic substances in inedible mushrooms are peptides (Yilmaz et al., 2014), and melittin, a peptide of 26 amino acids in length, is the principal active component of bee venom (Jamasbi et al., 
2014). Peptides can also cause allergic reactions in humans as peptides can be used as allergens in specific allergen immunotherapy (Larché, 2007).

The term food allergy refers to an immune response directed toward food and can be defined as an "adverse health effect arising from a specific immune response that occurs reproducibly on exposure to a given food" (Burks et al., 2012). The antibody responsible for most allergic reactions (type I hypersensitivities) belongs to the IgE isotype (Ribatti, 2016). Food allergy consists of two separate phases: sensitisation and elicitation. During the sensitisation phase, the immune system responds to the presence of an allergen with food-specific IgE antibody production by plasma cells that have differentiated from allergen-specific B lymphocytes (Burks et al., 2012). These IgE antibodies interact with low- and high-affinity IgE receptors (FceRII/CD23 and FceR1, respectively) on the surface of tissue mast cells or basophils and once the concentration of IgE antibodies on the mast cell and basophile is high enough, the elicitation phase can occur (Stone, Prussin, \& Metcalfe, 2010). The binding and crosslinking of the ingested (or inhaled) protein allergen with the specific IgE present on the cell membrane result in the release of histamine and other mediators of the inflammatory response triggering the various symptoms of allergy (Burks et al., 2012; Mittag et al., 2006; Panda, Tetteh, Pramod, \& Goodman, 2015). Although the toxicity and the allergenicity of food products must be assessed in vitro and in vivo, the European Food Safety Authority (EFSA) favours the use of in silico tools for initial prediction of potential allergens from food proteins (Christer et al., 2010). In addition, in silico tools can be used to predict the toxicity of peptides (Gupta et al., 2013).

The aim of this study was to generate and characterize novel bioactive blood protein hydrolysates from bovine $\gamma-, \alpha$-, and $\beta$-globulins which are currently underused as functional food ingredients. Two protein-rich fractions containing these proteins were generated from 
bovine blood by cold ethanol precipitation. These fractions were hydrolysed with the food grade enzyme papain (EC 3.4.22.2) and enriched using 1, 3, and $10 \mathrm{kDa}$ molecular weight cut-off (MWCO) filters. Peptides contained in the generated $1 \mathrm{kDa}$ fractions were characterized by LC-MS/MS. The identified peptides were assessed for potential toxicity and allergenicity in silico. 


\section{Materials and methods}

\subsection{Materials and reagents}

Formic acid (FA), ethanol, dimethyl sulfoxide (DMSO), acetonitrile (ACN), tri-chloroacetic acid (TCA), sodium citrate, papain from Carica papaya, the specific renin inhibitor Z-ArgArg-Pro-Phe-His-Sta-Ile-His-Lys-(Boc)-OMe, and the ACE-I inhibitor Captopril ${ }^{\circledR}$ were supplied by Sigma Aldrich (Dublin, Ireland). The DPP-IV inhibitor screening assay kit, containing the DPP-IV inhibitor sitagliptin, and the renin inhibitor screening assay kit were supplied by Cambridge BioSciences (Cambridge, England, UK). The ACE-I inhibition assay kit was supplied by NBS Biologicals Ltd. (Cambridgeshire, England, UK). All other chemicals used were of analytical grade.

\subsection{Blood collection and globulin fractionation procedure}

Whole bovine blood was collected at time of slaughter under hygienic conditions from the abattoir at the Teagasc Food Research Centre, Ashtown, Dublin 15, Ireland. All animals slaughtered were Charolais cross heifer breed and were aged between 23 and 24 months at the time of slaughter. Sodium citrate solution was used as an anticoagulant and was added immediately to blood following collection at a final concentration of $1.5 \%(\mathrm{w} / \mathrm{v})$. Blood was chilled to $4{ }^{\circ} \mathrm{C}$ and handled carefully to minimize hemolysis.

Whole blood cells were separated from plasma by centrifugation at $4^{\circ} \mathrm{C}$ and $10000 \times \mathrm{g}$ for 10 minutes using a Sigma 6K10 centrifuge (Sigma Laborzentrifugen GmbH, Osterode am Harz, Germany). Plasma was kept at $4{ }^{\circ} \mathrm{C}$, filtered through glass wool and freeze-dried using an industrial scale freeze-drier FD 80 model (Cuddon Engineering, Marlborough, New Zealand). The temperature was maintained at less than $35{ }^{\circ} \mathrm{C}$ during the freeze-drying process. Two fractions enriched for $\gamma$ - and $\alpha$ - and $\beta$-globulins were obtained from the freeze dried extract 
by precipitation following a previously described method (Álvarez, Bances, Rendueles, \& Díaz, 2009). Briefly, a protein fraction, rich in $\gamma$-globulins, labelled as FI, was precipitated by addition of ethanol to the serum at a final concentration of $19 \%(\mathrm{v} / \mathrm{v})$. The $\mathrm{pH}$ was adjusted to 7.2 by addition of $\mathrm{NaOH}$. Furthermore, a protein fraction, rich in $\alpha$ - and $\beta$-globulins, labelled as FII, was precipitated by adjustment of the $\mathrm{pH}$ to 5.5 and subsequent addition of ethanol to a final concentration of $40 \%(\mathrm{v} / \mathrm{v})$. Ethanol was added drop by drop and the process was carried out in an ice bath to minimise protein denaturation. The generated protein-rich fractions FI and FII were separated by centrifugation at $4{ }^{\circ} \mathrm{C}$ and $10,000 \times \mathrm{g}$ for 5 minutes, resuspended in Milli Q water, frozen, and freeze-dried.

The total protein content was determined in duplicate using a LECO FP628 Protein analyser (LECO Corp., MI, USA) based on the Dumas method and according to AOAC method $992.15,1990$. The conversion factor of 6.25 was used to convert total nitrogen to protein. The total protein content and yields were calculated per litre of blood throughout the separation. Moisture and ash content were determined gravimetrically in accordance with previously described methods (Kolar, 1992).

\subsection{Enzymatic hydrolysis of FI and FII}

Papain hydrolysates of FI and FII were prepared in triplicate using a BioFlo 110 Modular Benchtop fermenter (New Brunswick Scientific Co., Cambridge, England, UK) with agitation, temperature, and $\mathrm{pH}$ control. A substrate solution was prepared by resuspending the dried FI and FII fractions separately in MilliQ purified water at a concentration of $10 \mathrm{~g} / \mathrm{L}$ at a total volume of $500 \mathrm{~mL}$. Temperature and $\mathrm{pH}$ conditions were adjusted to $65^{\circ} \mathrm{C}$ and $\mathrm{pH} 6.5$ respectively. The $\mathrm{pH}$ was kept constant using $0.1 \mathrm{M} \mathrm{NaOH}$. Agitation was maintained at a constant of $350 \mathrm{rpm}$. Once the optimum $\mathrm{pH}$ and temperature conditions were achieved, the 
enzyme papain (activity $\geq 3 \mathrm{U} / \mathrm{mg}$ ) was added in a substrate to enzyme ratio of 100:1 (w/w). After $24 \mathrm{~h}$, the enzyme papain was heat-deactivated at $95{ }^{\circ} \mathrm{C}$ for $10 \mathrm{~min}$ in a water bath.

Four fractions were generated from each bovine globulin protein hydrolysate. The first fraction generated from FI and FII was termed as non-ultrafiltered hydrolysate and was labelled as FI-NUFH and FII-NUFH, respectively. Fractions two, three and four were obtained by MWCO filtration of the whole hydrolysates using 1, 3, and $10 \mathrm{kDa}$ MWCO membranes separately (Millipore, Tullagreen, Carrigtwohill, Co. Cork, Ireland). The fractions obtained from FI-NUFH using 1, 3, and $10 \mathrm{kDa}$ MWCO membranes were labelled as FI-1UFH, FI-3UFH, and FI-10UFH, respectively. In addition, the fractions obtained from FII-NUFH using 1, 3, and $10 \mathrm{kDa}$ MWCO membranes were labelled as FII-1UFH, FII3UFH, and FII-10UFH, respectively. All fractions were frozen, freeze-dried, and stored at $20{ }^{\circ} \mathrm{C}$ until further use.

\subsection{Electrophoretic separation using tris-tricine peptide gels}

Electrophoresis was carried out using a BIO-RAD Mini-PROTEAN® 3 cell System (BioRad Laboratories Ltd., Hertfordshire, UK) and a 10 well Mini-PROTEAN® Tris-Tricine gel according to the manufacturers' instructions. Commercial low (1.7-42 kDa in size) and high (2-250 kDa in size) molecular weight (MW) markers were used.

\subsection{Renin inhibition assay}

This assay was carried out using a renin inhibitor screening assay kit in accordance with the manufacturers' instructions. All fractions were assayed at a concentration of $1 \mathrm{mg} / \mathrm{mL}$ DMSO in triplicate and standard deviations (S.D.) calculated. Fluorescence intensity was recorded with a FLUOstar Omega microplate reader (BMG LABTECH GmbH, Offenburg, Germany) 
using an excitation wavelength of $340 \mathrm{~nm}$ and an emission wavelength of $500 \mathrm{~nm}$. The known renin inhibitor Z-Arg-Arg-Pro-Phe-His-Sta-Ile-His-Lys-(Boc)-OMe was used as a positive control and renin $\mathrm{IC}_{50}$ values were determined in triplicate for active hydrolysates by plotting the percentage of renin inhibition as a function of the concentration of test compound.

\subsection{ACE-I inhibition assay}

This assay was carried out using an ACE-I inhibitor assay kit in accordance with the manufacturers' instructions. All fractions were assayed at a concentration of $1 \mathrm{mg} / \mathrm{mL}$ HPLC grade water in triplicate and means and S.D. were calculated. The known ACE-I inhibitor captopril was used as a positive control at a concentration of $1 \mathrm{mg} / \mathrm{mL}$. Absorbance was measured with a FLUOstar Omega microplate reader (BMG LABTECH GmbH, Offenburg, Germany) at $450 \mathrm{~nm}$. ACE-I $\mathrm{IC}_{50}$ values were determined for active hydrolysates by plotting the percentage of inhibition as a function of the concentration of test compound.

\subsection{DPP-IV inhibition assay}

This assay was carried out using a DPP-IV inhibitor screening assay kit in accordance with the manufacturers' instructions. All hydrolysates were assayed in triplicate and means and S.D. were calculated. The known DPP-IV inhibitor IPI was used as a positive control. Fluorescence intensity was recorded with a FLUOstar Omega microplate reader (BMG LABTECH GmbH, Offenburg, Germany) using an excitation wavelength of $355 \mathrm{~nm}$ and an emission wavelength of $460 \mathrm{~nm}$. DPP-IV $\mathrm{IC}_{50}$ values were determined for active hydrolysates by plotting the percentage of inhibition as a function of the concentration of test compound.

\subsection{Peptide identification by LC-MS/MS}


The peptidic content of FI-1UFH and FII-1UFH was analysed using a Thermo Scientific Q Exactive $^{\mathrm{TM}}$ mass spectrometer connected to a Dionex UltiMate ${ }^{\circledR} 3000$ RSLCnano LC System. The samples were suspended in $0.1 \%$ FA in HPLC grade water and cleaned using Millipore ${ }^{\circledR}$ C18 ZipTips prior to LC-MS/MS. The sample was loaded onto Biobasic Picotip Emitter (120 mm length, $75 \mu \mathrm{m}$ ID) packed with Reprocil Pur C18 $(1.9 \mu \mathrm{m})$ reversed phase media and was separated by an increasing ACN gradient over 60 minutes at a flow rate of $250 \mathrm{nl} / \mathrm{min}$. The mass spectrometer was operated on positive ion mode with a capillary temperature of $220^{\circ} \mathrm{C}$, and with a potential of $2.3 \mathrm{kV}$ applied to the emitter. All data were acquired with the mass spectrometer operating in automatic data-dependent switching mode. A high resolution (70,000 FWHM) MS scan (m/z 300 to m/z 1600) was performed using the Q-Exactive ${ }^{\mathrm{TM}}$ to select the 12 most intense ions prior to MS/MS analysis using higher-energy collisional dissociation.

The raw data was de novo sequenced and searched against the bovine subset of the UniProtKB/Swiss-Prot database using the search engine of PEAKS Studio 7 for peptides cleaved with no specific enzyme. At least one unique peptide was required to identify a protein. Each peptide used for protein identification met specific PEAKS parameters (only peptide scores that corresponded to a false discovery rate of $\leq 1 \%$ were accepted from the PEAKS database search). Each sample was run three times and results shown are the combined technical replicates. Peptide sequences, their position inside the parent proteins, their observed masses, and their retention times were provided by the PEAKS Studio software. In addition, the amino acid concentration of identified proteins was determined using ProtParam, which computes the physicochemical properties of a protein from its amino acid sequence (Gasteiger et al., 2003).

\subsection{In silico prediction of allergenicity and toxicity}


The peptides identified in FI-1UFH and FII-1UFH were assessed for potential toxicity in silico using ToxinPred, available at http://www.imtech.res.in/raghava/toxinpred/ (Gupta et al., 2013). In addition, the above mentioned peptides were assessed for potential allergenicity using two different tools, AlgPred, available at http://www.imtech.res.in/raghava/algpred/ (Saha \& Raghava, 2006) and AllerTOP, available at http://www.pharmfac.net/allertop/ (Dimitrov, Bangov, Flower, \& Doytchinova, 2014). Two different approaches were used for prediction of allergenicity using AlgPred: (i) the SVM module based on amino acid composition prediction approach and (ii) the MEME/MAST motif prediction approach.

\subsection{Statistical analysis}

All tests were replicated three times and mean values and S.D. were calculated. ANOVA one-way analysis was carried out using Minitab ${ }^{\circledR}$ v17 (Minitab Ltd., England, UK). Where significant differences were present, a Tukey pairwise comparison of the means was conducted to identify where the sample differences occurred. The criterion for statistical significance was $\mathrm{p}<0.05$. 


\section{Results}

\subsection{Isolation of bovine $\alpha$-, $\beta$-, and $\gamma$-globulins}

The yield of FI and FII was calculated per litre of blood and was found to be $5.9 \pm 0.4$ and $10.2 \pm 0.1 \mathrm{~g} / \mathrm{L}$, respectively. Moreover, the total protein content of FI and FII was $88.1 \pm 0.1$ and $88.8 \pm 0.1 \%$, respectively. The total moisture and ash content values of FI and FII were $7.59 \pm 0.06$ and $1.28 \pm 0.08 \%$, and $5.69 \pm 0.15$ and $1.37 \pm 0.22 \%$, respectively. The isolated protein fractions were analysed by electrophoresis using a tris-tricine peptide gel at a concentration of $10-20 \%$ in accordance with manufacturers' instructions (Bio-Rad Laboratories Ltd., Hertfordshire, UK). Results, presented in Figure 1, show a large number of proteins with MW ranging between 25-250 $\mathrm{kDa}$. These proteins were subsequently identified using MS and a total of 37 and 84 proteins were identified from FI and FII, respectively (UniProt accession numbers and protein names found in Appendix A). Briefly, these proteins included complement $\mathrm{C} 3 \quad$ (Q2UVX4|CO3_BOVIN), apolipoprotein A-II (P81644|APOA2_BOVIN), serotransferrin (Q29443|TRFE_BOVIN), and prothrombin (P00735|THRB_BOVIN) identified in FI and apolipoprotein H (P17690|APOH_BOVIN), histidine-rich glycoprotein (P33433|HRG_BOVIN), and plasminogen (P06868|PLMN_BOVIN) identified in FII. The average mass of these proteins was 187.2, $11.2,77.7,70.5,38.2,44.4$, and $91.2 \mathrm{kDa}$, respectively. Traces of blood proteins such as fibrinogen and bovine serum albumin were identified in both fractions.

The amino acid sequence of these proteins was accessed from the UniProt database, available at http://www.uniprot.org/, and their amino acid composition was calculated using ProtParam (data not shown). Results revealed that, for example, bovine complement $\mathrm{C} 3$ presents high concentrations of leucine (9.2\%) and isoleucine (5.8\%), compared to other residues such as cysteine $(1.6 \%)$, histidine $(1.9 \%)$, or methionine (1.9\%). In addition, apolipoprotein A-II also 
showed high concentration of leucine (16.0\%) and bovine plasminogen showed a high concentration of proline (9.2\%) compared to other residues such as methionine.

3.2 In vitro assessment of ACE-I, renin, and DPP-IV inhibitory activity of the generated hydrolysates and enriched fractions

FI and FII were hydrolysed with the food-grade enzyme papain and enriched by 1,3 , and 10 $\mathrm{kDa}$ MWCO membranes into four fractions. The in vitro renin and ACE-I inhibitory activity of these hydrolysates was calculated and results are shown in Figure 2. At a concentration of $1 \mathrm{mg} / \mathrm{mL}$, the fractions FI-1UFH was the most active and inhibited ACE-I by $83.08 \pm 0.25 \%$. The ACE-I IC $_{50}$ values were calculated for fractions FI-NUFH, FI-1UFH, FI-3UFH, and FI10UFH, and were $0.24 \pm 0.03,0.10 \pm 0.01,0.09 \pm 0.01$, and $0.19 \pm 0.04 \mathrm{mg} / \mathrm{mL}$, respectively. Moreover, the ACE-I IC $_{50}$ value of fractions FII-NUFH, FII-1UFH, FII-3UFH, and FII10UFH were $0.95 \pm 0.06,0.45 \pm 0.07,0.39 \pm 0.07$, and $0.90 \pm 0.05 \mathrm{mg} / \mathrm{mL}$, respectively. Furthermore, the renin inhibitory activity of the enriched papain hydrolysates was measured at a concentration of $1 \mathrm{mg} / \mathrm{mL}$. The renin inhibitory activity of the generated hydrolysates was lower compared to that of ACE-I. Purification by ultrafiltration of FI-NUFH and FIINUFH led to a significant decrease in the renin-inhibiting activity of FI-1UFH and FII-1UFH compared to FI-NUFH and FII-NUFH, respectively $(\mathrm{p}<0.05)$.

Fractions FI-NUFH and FII-NUFH were the most active inhibiting DPP-IV and inhibited this enzyme by over $50 \%$. DPP-IV $\mathrm{IC}_{50}$ values were $1.03 \pm 0.02$ and $0.99 \pm 0.02 \mathrm{mg} / \mathrm{mL}$ for FINUFH and FII-NUFH, respectively. A slight decrease was observed in the DPP-IV-inhibiting activity of FI-NUFH and FII-NUFH after enrichment by MWCO filtration $(p<0.005)$.

\subsection{Identification of peptides by $L C-M S / M S$}


As mentioned previously, the most active ACE-I inhibitory hydrolysates were FI-1UFH and FII-1UFH. The peptides contained in these fractions were identified by HPLC-MS/MS. A total of 626 and 2246 unique peptides were identified in FI-1UFH and FII-1UFH, respectively. Table 1 lists the peptides identified in F1-UFH and FII-UFH which were predicted to be allergenic or potentially allergenic using both, AlgPred and AllerTOP. In addition, Table 2 lists the peptides which were predicted to be non-allergens using both in silico tools and which showed PeptideRanker score over 0.50. Due to the large number of identified peptides, their amino acid sequences and their parent proteins are listed as supplementary data (Appendix B). Identified peptides included QKVQPYLDEFQK which corresponded to bovine apolipoprotein A-I (P15497|APOA1_BOVIN).

\subsection{Determination of toxicity and allergenicity of identified peptides using in silico methods}

The peptides identified in FI-1UFH and FII-1UFH were assessed for potential allergenicity in silico using two independent in silico tools. As mentioned previously, two different approaches were used for prediction of allergenicity using AlgPred: (i) the SVM module based on amino acid composition prediction approach and (ii) the MEME/MAST motif prediction approach. MEME is a tool for discovering motifs in a group of related protein sequences and MAST is a tool used for searching biological sequence databases for sequences that contain one or more of a group of known motifs (Saha \& Raghava, 2006). In addition, SVM are supervised learning models used for classification, regression, and outlier detection. AlgPred implements a SVM which uses a radial basis function kernel and the input vectors were amino acid composition, used for this study, and di-peptide composition of each protein sequence (Saha \& Raghava, 2006). AlgPred can only analyse peptides longer than ten amino acids in length and for this reason data on potential allergenicity of shorter peptides is not available. Numerous peptides from those tested were predicted to retain the allergenicity 
of their parent protein using the SVM module based on amino acid composition approach of AlgPred. Indeed, 148 and 4 peptides from FI and 984 and 88 from FII were labelled as allergens or potential allergens, respectively, based on the predicted potential of these peptides to retain the allergenicity of their parent protein. Only 4 peptides from FI and 152 from FII were predicted to be non-allergens using this predictive approach. Potential allergenic peptides included AAVYNHFISDGVK, VSSDLWGEKPK, and VPINDGNGEAILK, generated from bovine complement C3, and the peptides EFREGARQKVQ and ISNNEADAVTR, generated from apolipoprotein A-I and serotransferrin, respectively. In addition, none of the studied peptides were predicted to be allergens using the AlgPred motif based approach using MEME/MAST.

The identified peptides were also assessed for potential allergenicity using AllerTOP, an alignment-free server for in silico prediction of allergens based on physicochemical properties of the amino acid sequence (ACC protein sequence transformation, amino acid zdescriptors, and $\mathrm{k}$ nearest neighbours clustering) (Dimitrov et al., 2014). Results revealed that 131 peptides from FI and 1027 from FII probably retained the allergenicity of their parent protein. In addition, 131 peptides from FI and 1219 from FII were predicted to be probable non-allergens using AllerTOP. These included the peptides HYLDSTDQWEKFG and MTEDAIDGERLK which corresponded to $\mathrm{f}(1025-1037)$ and $\mathrm{f}(989-1000)$ of bovine complement C3. The peptides HYLDSTDQWEKFG and MTEDAIDGERLK were predicted to have a $66.6 \%$ of probability of being an inhalant and a food allergen, respectively. Other peptides which were predicted retain the allergenicity of their parent protein were QGRESKPLTA and DSWEKYL. Both peptides were generated from bovine fibronectin and had a probability of $99.9 \%$ of being food allergens. A number of peptides identified within FI-1UFH and FII-1UFH, listed in Table 2, were predicted to be non-allergens or probable non-allergens using both, AlgPred and AllerTOP. The PeptideRanker scores of these peptides 
were calculated and are shown in Table 2. The PeptideRanker score of every identified peptide was listed in Appendix C. Peptides with high PeptideRanker scores include HFPFL (0.99), HNSMFF (0.96), and WSPPPR (0.95).

The peptides contained in FI-1UFH and FII-1UFH were also assessed for potential toxicity in silico using ToxinPred (Gupta et al., 2013). Results suggest that the generated hydrolysates were non-toxic as no potentially toxic peptides were identified.

Overall, 2872 peptides, identified in two protein fractions derived from bovine blood proteins generated using papain, were assessed for in silico potential allergenicity using three different approaches. The majority of the peptides identified in FI were predicted to maintain the allergenicity of their parent protein and were labelled as allergens or potential allergens $(89.7$ and $2.5 \%$, respectively) by the software. In addition, approximately half of the peptides identified in this fraction $(50.3 \%)$ were predicted to retain the allergenicity of their parent protein using AllerTOP. This trend was similar to that obtained with the peptides identified in FII, where 80.1 and $7.2 \%$ of the analysed peptides were predicted to be allergens or potential allergens using AlgPred and 45.7\% were predicted to be probable allergens using AllerTOP. 


\section{Discussion}

\subsection{Isolation of bovine $\alpha$-, $\beta$-, and $\gamma$-globulins}

Globulins comprise a heterogeneous group of proteins that include immunoglobulins, carrier proteins, and enzymes, and account for $40 \%$ of the plasma protein content of blood (Parés, Toldrà, Saguer, \& Carretero, 2014). Bovine $\alpha$-, $\beta$ - and $\gamma$-globulins represent approximately $0.51,0.53$, and $0.63 \%$ of the total content of whole bovine blood, respectively (Bah et al.,

2013). Numerous $\alpha$-, $\beta$ - and $\gamma$-globulins were identified in FI and FII as well as hemoglobin, fibrinogen, and bovine serum albumin. Results align well with a previous study where proteins such as bovine serum albumin were identified in the globulin fractions after cold ethanol precipitation of blood proteins (Moure, Rendueles, \& Diaz, 2003).

The amino acid composition analysis of the identified proteins revealed relatively high concentrations of tyrosine, leucine, isoleucine, and proline compared to other residues including methionine, alanine, cysteine, or histidine. Although the activity of peptides is based on their inherent amino acid composition and sequence, the high content of these amino acids in the isolated proteins suggested their potential for use for the generation of renin, ACE-I, and DPP-IV inhibitory peptides. Residues with large bulky and hydrophobic side-chains such as tryptophan, tyrosine, proline, and phenylalanine were suggested as the most effective residues in ACE-I inhibitory di-peptides previously (Wu, Aluko, \& Nakai, 2006). Amino acid residues with small as well as hydrophobic side-chains such as valine, leucine, and isoleucine were also suggested for the N-terminal side of ACE-I inhibitors (Wu et al., 2006). In addition, hydrophobic residues and a bulky or aromatic group at the Cterminus position were observed to be the most effective for renin inhibition (Li \& Aluko, 2010). 


\subsection{In vitro assessment of $A C E-I$, renin, and DPP-IV inhibitory activity}

FI and FII were hydrolysed with the food-grade enzyme papain and enriched by 1, 3, and 10 kDa MWCO membranes into four fractions. Tris-tricine peptide gel electrophoresis analysis, shown in Figure 1, demonstrated that both isolated protein fractions were hydrolysed by papain and that the hydrolysates generated consisted mainly of peptides with MW under 20 $\mathrm{kDa}$. This is clear from the gel as the bands present at higher MW no longer appear in the hydrolysed fractions. FI-NUFH and FII-NUFH were further enriched by MWCO filtration using 1,3 , and $10 \mathrm{kDa}$ membranes.

The generated hydrolysates and the enriched fractions generated from them were assessed for in vitro renin, ACE-I, and DPP-IV inhibitory potential. Purification by MWCO filtration led to an increase in the ACE-I inhibitory activity of FI-1UFH and FII-1UFH compared to the FINUFH and FII-NUFH, respectively $(\mathrm{p}<0.05)$. It is well documented that peptidic ACE-I inhibitors usually consist of short amino acid sequences (Wu et al., 2006), and high MW peptides in the NUFH and in the 10UFH fractions may be responsible for the observed decrease in ACE-I inhibitory activity. These results are consistent with previous studies, where sequential ultrafiltration of blood protein hydrolysates with 10,3 and, $1 \mathrm{kDa}$ membranes resulted in increased activity (Hyun \& Shin, 2000). Results obtained herein are similar to those obtained from Alcalase hydrolysates of rapeseed protein (He et al., 2013), peanut protein isolate and its Alcalase hydrolysates (Jamdar et al., 2010), and Alcalase hydrolysates of kidney bean protein and its purified peptide fractions (Mundi \& Aluko, 2014). Hyun and Shin (2000) generated hydrolysates of whole bovine plasma and plasma proteins with different commercially available enzymes. The most active fraction, the $1 \mathrm{kDa}$ fraction of an Alcalase hydrolysate of bovine serum albumin, presented an $\mathrm{IC}_{50}$ value of 0.12 $\mathrm{mg} / \mathrm{mL}$. 
Although di-peptides were previously suggested as the most effective for renin inhibition (Mundi \& Aluko, 2014), purification of FI-NUFH and FII-NUFH by MWCO filtration led to a significant decrease in the renin inhibitory activity of FI-1UFH and FII-1UFH $(p<0.05)$. It was previously suggested that the nature and position of the amino acid residues rather than the size of the peptide play a major role in the enhancement of renin. At a concentration of 1 $\mathrm{mg} / \mathrm{mL}$, the fraction FII-NUFH was the most active and was found to inhibit renin by $45.08 \pm$ $1.56 \%$. This fraction presented an $\mathrm{IC}_{50}$ value of $1.18 \pm 0.02 \mathrm{mg} / \mathrm{mL}$. Results obtained in this study are similar to those obtained from Alcalase hydrolysates of kidney bean protein, which inhibited renin by $20-40 \%$ at a concentration of $1 \mathrm{mg} / \mathrm{mL}$ (Mundi \& Aluko, 2014) and to enzymatic hydrolysates of flaxseed protein with renin $\mathrm{IC}_{50}$ values ranging $1.22-2.81 \mathrm{mg} / \mathrm{mL}$ (Udenigwe, Lin, Hou, \& Aluko, 2009). Results obtained herein are also comparable to those obtained from papain hydrolysates of bovine blood proteins including fibrinogen (Lafarga, Rai, O'Connor, \& Hayes, 2015) and serum albumin (Lafarga, Aluko, Rai, O'Connor, \& Hayes, 2016).

FI-NUFH and FII-NUFH were the most active inhibiting DPP-IV. These results contrast with previous studies where the removal of higher MW fractions led to an increase in the DPP-IV inhibitory activity in vitro (Velarde-Salcedo et al., 2013). FI-NUFH and FII-NUFH showed lower DPP-IV $\mathrm{IC}_{50}$ values than those obtained previously from trypsin hydrolysates of Amaranthus hypochondriacus $\mathrm{L}$. proteins with $\mathrm{IC}_{50}$ values ranging from 1.2 to $2.0 \mathrm{mg} / \mathrm{mL}$, depending on the enzyme to substrate ratio (Velarde-Salcedo et al., 2013), and Flavourzyme hydrolysates of Atlantic salmon gelatine which displayed an $\mathrm{IC}_{50}$ value of $1.35 \mathrm{mg} / \mathrm{mL}$ (LiChan, Hunag, Jao, Ho, \& Hsu, 2012). Moreover, the papain hydrolysates generated in this study were also more active inhibiting DPP-IV than trypsin hydrolysates of whey protein with an $\mathrm{IC}_{50}$ value of $1.51 \mathrm{mg} / \mathrm{mL}$, where the penta-peptide IPAVF, corresponding to $\beta$ - 
lactoglobulin $f(78-82)$ and with an $\mathrm{IC}_{50}$ value of $44.7 \mu \mathrm{M}$ was responsible for the observed activity (Silveira, Martínez-Maqueda, Recio, \& Hernández-Ledesma, 2013).

Peptides generated by the action of papain on blood proteins such as fibrinogen and bovine serum albumin may have contributed to the observed enzymatic inhibitory activity of the globulin-enriched protein isolate generated in this study, as both sources were recently suggested as sources of bioactive peptides with ACE-I, renin, or DPP-IV inhibitory activities after cleavage with papain (Lafarga, Aluko, et al., 2016; Lafarga et al., 2015). In addition, previous studies demonstrated the in vivo antihypertensive potential of a papain hydrolysate of bovine $\alpha$ - and $\beta$-globulins in spontaneously hypertensive rats after administration at a dosage of $200 \mathrm{mg} / \mathrm{kg}$ body weight (Lafarga, Gallagher, Aluko, Auty, \& Hayes, 2016).

\subsection{In silico prediction of allergenicity}

Food allergy affects approximately $8 \%$ of children and $1-2 \%$ of adults, and its frequency is increasing (Kim, Lee, Song, Kim, \& Ahn, 2011). Most allergens reacting with IgE antibodies are proteins found in peanuts, soybeans, tree nuts, milk, egg, fish, crustaceans, and wheat (Panda et al., 2015; Turnbull, Adams, \& Gorard, 2015). However, allergic reactions, anaphylaxis, urticarial, or angioedema were observed after consumption of red meat previously (Fiocchi, Restani, \& Riva, 2000; Hemmer, Mayer, \& Jarisch, 2011; Martelli, De Chiara, Corvo, Restani, \& Fiocchi, 2002). There is cross-reactivity between different meats, such as beef and pork, as well as between milk and mammalian meats (Kazatsky \& Wood, 2016). Patients with severe allergic reactions after consumption of red meat showed $\operatorname{IgE}$ antibodies against the carbohydrate epitope galactose- $\alpha$-1,3-galactose (Hamsten et al., 2013), and numerous studies suggested an association among tick bites and red meat allergy (Commins \& Platts-Mills, 2013; Hamsten et al., 2013; Van Nunen, O'Connor, Clarke, Boyle, \& Fernando, 2009). In addition, previous studies demonstrated allergic reactions to bovine 
proteins such as gelatine (Purello-d'ambrosio, Gangemi, La Rosa, Merendino, \& Tomasello, 2000), myoglobin (Fuentes, Palacios, Garcés, Caballero, \& Moneo, 2004), bovine gamma globulin (Kazatsky \& Wood, 2016), and serum albumin (Chruszcz et al., 2013).

As mentioned previously, EFSA encourages the use of in silico tools for initial prediction of potential allergens from food proteins (Christer et al., 2010). There are two main types of bioinformatics-based allergen prediction tools. The first group consists of those based on searches for sequence similarities following the Codex alimentarius guidelines produced by the Food and Agriculture Organization (FAO) and the World Health Organization (WHO), which states that a "protein is potentially allergenic if it either has an identity of over six contiguous amino acids or a minimum of $35 \%$ sequence similarity when compared to known allergens" (Dimitrov et al., 2014). The second group of predictive tools consists of databases that utilise methods based on identifying conserved, allergenicity-related linear motifs (Dimitrov et al., 2014). This approach assumes that allergenicity is a linearly coded property and this led to the development of a novel alignment-independent methods based on the autoand cross-covariance transformation of protein sequences into uniform, equal vectors (Dimitrov et al., 2014).

AlgPred, available at http://www.imtech.res.in/raghava/algpred/, integrates various approaches in order to predict allergenic proteins accurately (Saha \& Raghava, 2006). As mentioned previously, in this study, the prediction approaches used were two: the motif based approach using MEME/MAST and the SVM module based on amino composition approaches. Results obtained using the SVM module based on amino composition approach suggested that 152 peptides contained in FI and 1072 peptides contained in FII retained the allergenicity of their parent protein and were labelled as allergenic or potentially allergenic. Peptides identified in FI-1UFH and FII-1UFH presented just a few amino acid residues in 
length. These peptides do not usually adopt stable structures in solution (Irvine, 2003), reducing the presence of potential conformational epitopes. In addition, hydrolysates used as food ingredients usually undergo thermal treatment which destroys conformational epitopes and influences its interaction with other food ingredients (Rahaman, Vasiljevic, \& Ramchandran, 2016). However, and although enzymatic hydrolysis was previously shown to eliminate linear epitopes, the existence of linear epitopes depends on the degree of hydrolysis and type of enzyme used (Sabadin, Villas-Boas, de Lima Zollner, \& Netto, 2012). For this reason, peptides generated from bovine globulins using papain could potentially contain linear epitopes and retain the allergenicity of their parent protein. In addition, the enzyme papain, used in this study, is a known allergen (Tarlo et al., 1978). No allergenic peptides were predicted using the MEME/MAST predictive approach. This does not mean that the identified peptides cannot cause allergic reactions to humans after ingestion, as the authors and developers of AlgPred demonstrated that the motif-based approach had a low specificity and could show a high percentage (approximately 66\%) of wrong assignment of allergenicity. In addition, allergenicity results obtained using AllerTOP suggested that over $40 \%$ of the peptides contained in FI and FII could cause allergic reactions in humans after ingestion.

PeptideRanker, available at http://bioware.ucd.ie, is a useful in silico tool that may be used to identify among a set of peptides those that may be more likely to be bioactive (Mooney, Haslam, Pollastri, \& Shields, 2012). A number of peptides from those predicted to be nonallergens showed relatively high PeptideRanker scores (over 0.6) and showed potential for further in vitro and in vivo confirmation of bioactivity. However, this score is not a prediction of the degree of bioactivity but a prediction of how likely the peptide is to be bioactive. Results obtained using different predictive approaches and different in silico tools were not consistent as there were a number of peptides which were predicted to be allergens/nonallergens, depending of the in silico tool used for allergenicity prediction. These included 
GLIDEVDQDFTSR and RDGQERDAPIVK, generated from fibrinogen and fibronectin, respectively.

Results suggested that generated papain hydrolysates contain peptides which retained the allergenicity of their parent proteins, and their potential allergenicity should be further assessed in vitro and in vivo in order to correctly label products containing these hydrolysates in line with Food and Consumer (FIC) legislation - Regulation (EU) No.1169/2011. In vitro and in vivo assays include IgE binding tests, which measure the capacity of specific IgE from serum or allergic individuals to bind to the test peptides, the pepsin resistance and in vitro digestibility tests, as well as targeted serum screening and the use of animal models (Christer et al., 2010).

\subsection{In silico prediction of toxicity}

In this study, the identified peptides were originated from blood proteins, which are regularly consumed in numerous countries. In addition, enzymes used in the generation of peptides, such as papain, are generally obtained from edible parts of plants or animals which are considered as posing no health risk (Schaafsma, 2009). After ingestion of food, proteins are naturally hydrolysed in the gastrointestinal tract. This often results in the release of dipeptides, tri-peptides, and free amino acids which are transported across the intestine wall (Ponstein-Simarro Doorten, vd Wiel, \& Jonker, 2009). Protein hydrolysates and peptides with low MW are not generally toxic and are known to be less allergenic than their native protein and are widely used in the formulation of hypoallergenic infant foods (Høst \& Halken, 2004). However, proteins and peptides can be toxic. As mentioned previously, well-known toxic peptides include melittin, a peptide of 26 amino acids in length which is the principal active component of bee venom (Jamasbi et al., 2014). This peptide can target live cells such as red blood cells and bind to their membrane leading to lipid bilayer disruption and to hemolysis 
(Jamasbi et al., 2014). None of the identified peptides was predicted to be toxic using in silico analysis. However, the in silico assessment of toxicity is not enough and in vivo studies in animal models should be carried out before human consumption. The in vivo assessment of the toxicity of food products must be carried out following the guidelines proposed by international authorities, which requires large quantities of scientific evidence and tests which are usually carried out on vertebrate models, on vertebrate cell lines, or unicellular microbial species (Marques et al., 2011). Numerous peptide toxicity studies have been carried out in animal models to date (Dent et al., 2007; Ponstein-Simarro Doorten et al., 2009). 


\section{Conclusions}

In silico tools including ToxinPred, AlgPred, and AllerTOP were used to predict potential toxicity and allergenicity of over 2500 peptides which were identified from two papain hydrolysates of bovine globulin proteins. These hydrolysates were generated using the foodgrade enzyme papain and were shown to have renin, ACE-I, and DPP-IV inhibitory activities which showed potential for use as ingredients in functional foods. However, a large number of the peptides identified using MS within the hydrolysate were predicted to have an allergenic nature using in silico methods and could cause an allergic reaction to humans if ingested. Further in vitro and in vivo studies should be carried out in order to demonstrate allergenicity and to ensure the correct labelling of these hydrolysates if used in the food industry. 


\section{Acknowledgements}

Tomas Lafarga is in receipt of a Teagasc Walsh Fellowship. This work forms part of the ReValueProtein Research Project (Grant Award No. 11/F/043) which is supported by the Irish Department of Agriculture, Food and the Marine (DAFM) and the Food Institutional Research Measure (FIRM) both funded by the Irish Government under the National Development Plan 2007-2013. This work was also supported by the EU COST Action imPARAS 1402. The authors would like to acknowledge Anne Maria McAuliffe from Teagasc Food Research Centre Moorepark and Ms Karen Hussey from Teagasc Food Research Centre Ashtown for their collaboration in the amino acid composition analysis and in the compositional methods used. 


\section{Figure legends}

Figure 1 (A): Tris-tricine peptide gel of the isolated FI protein fraction and the generated papain hydrolysate

MW markers are shown in columns $(a)$ and $(d)$, respectively. MW marker values are expressed in $\mathrm{kDa}$. The isolated FI fraction is shown in column $(b)$ and FI-NUFH is shown in column (c).

Figure 1 (B): Tris-tricine peptide gel of the isolated FII fraction and the generated papain hydrolysate

MW markers are shown in columns $(a)$ and $(d)$, respectively. MW marker values are expressed in $\mathrm{kDa}$. The isolated FII fraction is shown in column (b) and FII-NUFH is shown in column $(c)$. 
Figure 2: renin, ACE-I, and DPP-IV in vitro inhibitory properties of the papain hydrolysates generated from (A) FI and (B) FII.

Z-Arg-Arg-Pro-Phe-His-Sta-Ile-His-Lys-(Boc)-OMe, sitagliptin, and captopril were used as positive controls at a concentration of $1 \mathrm{mg} / \mathrm{mL}$ for renin, DPP-IV, and ACE-I inhibition, respectively. Enzyme inhibition is expressed as per cent inhibition and the values represent the means of three independent experiments \pm standard error of the mean (SEM). For each bioactivity tested, bars with different letters have mean values that are significantly different $(p<0.05)$. 
Figure 1

(A)

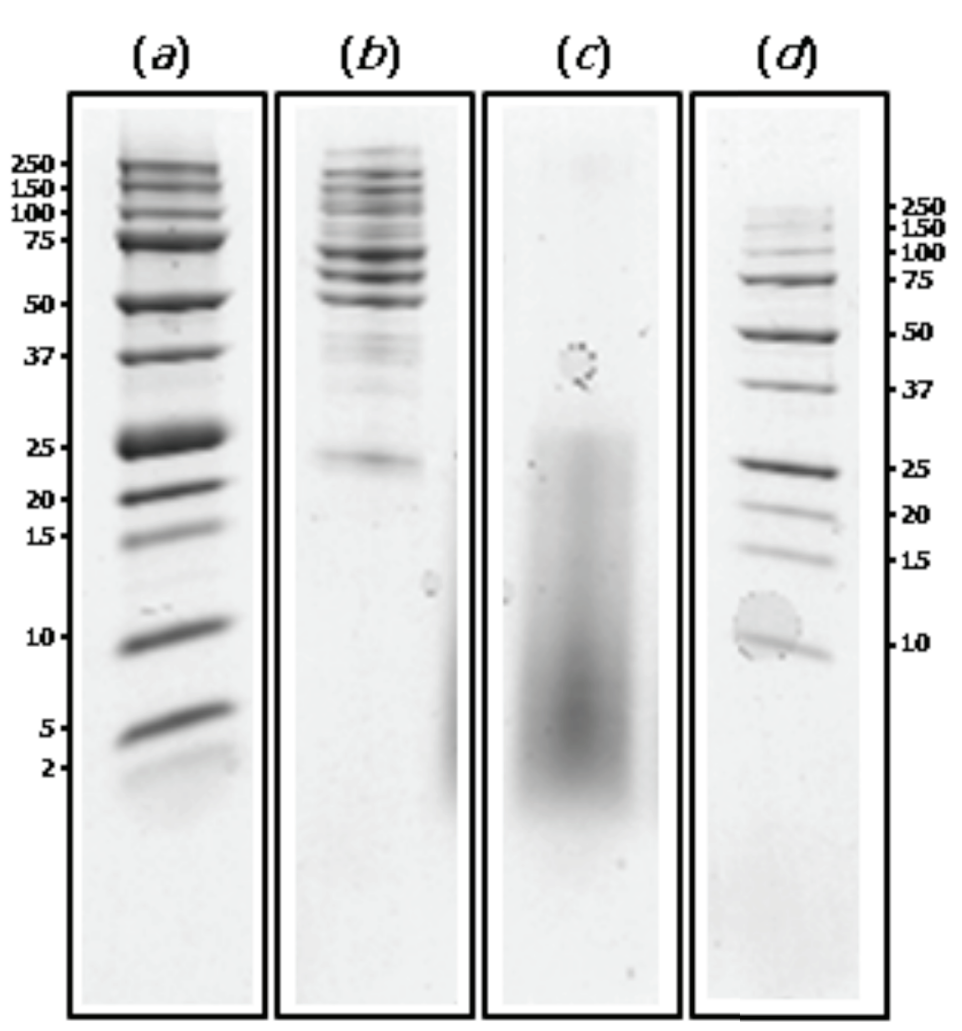

(B)

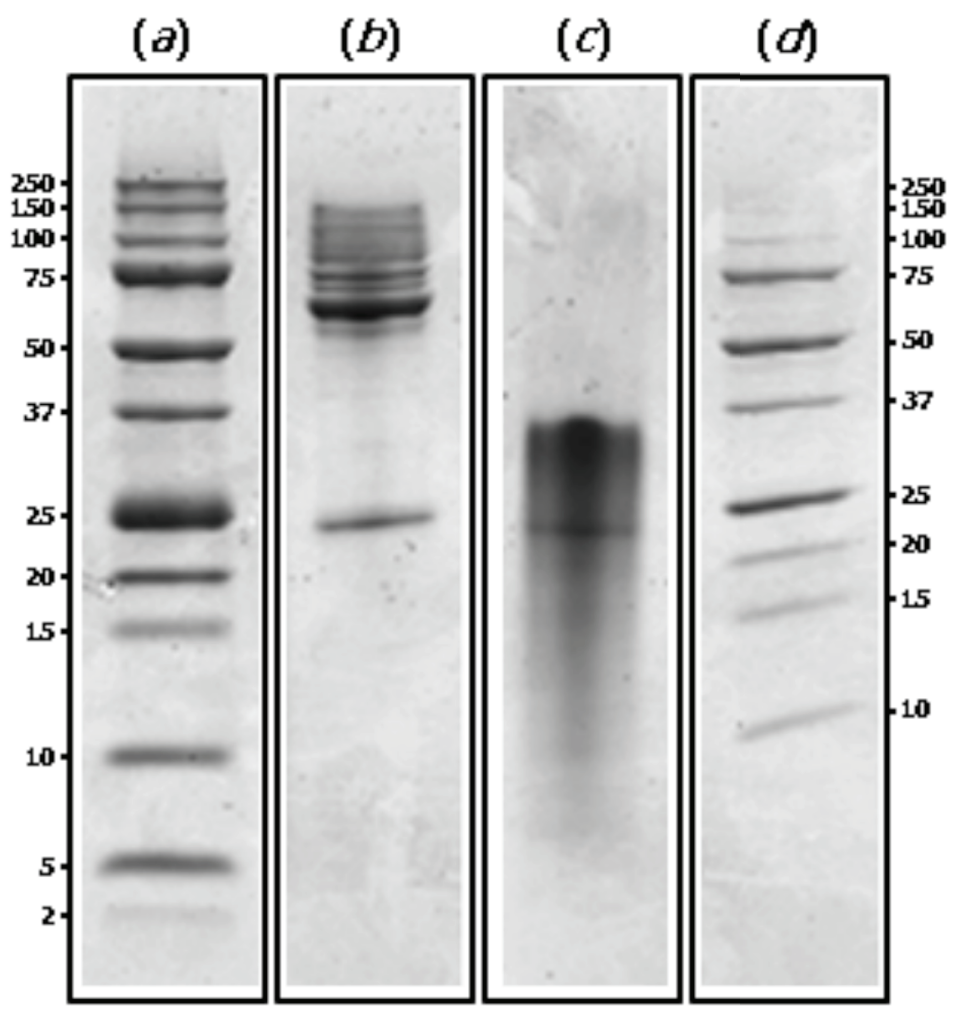


Figure 2

A.

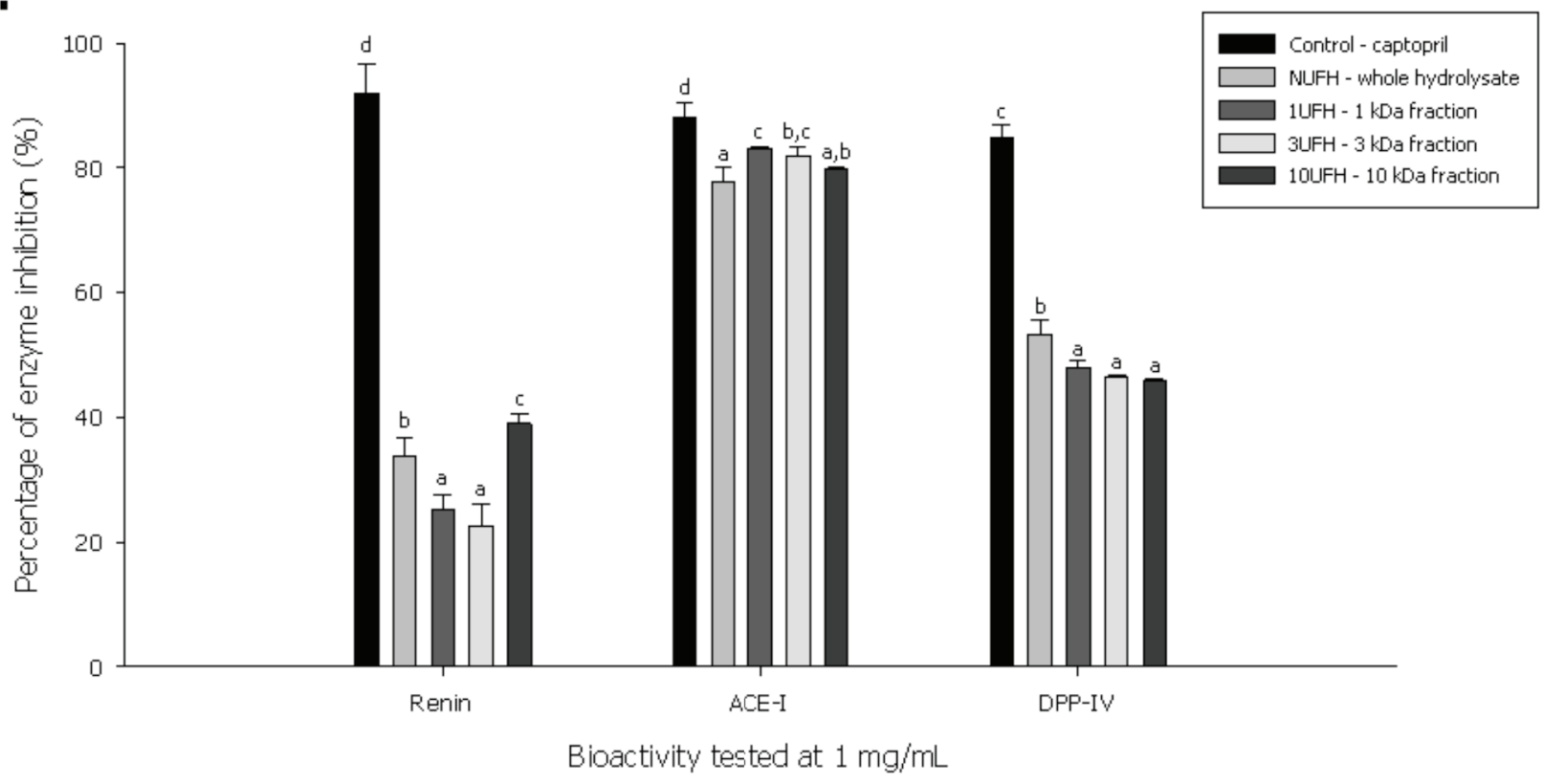

B.

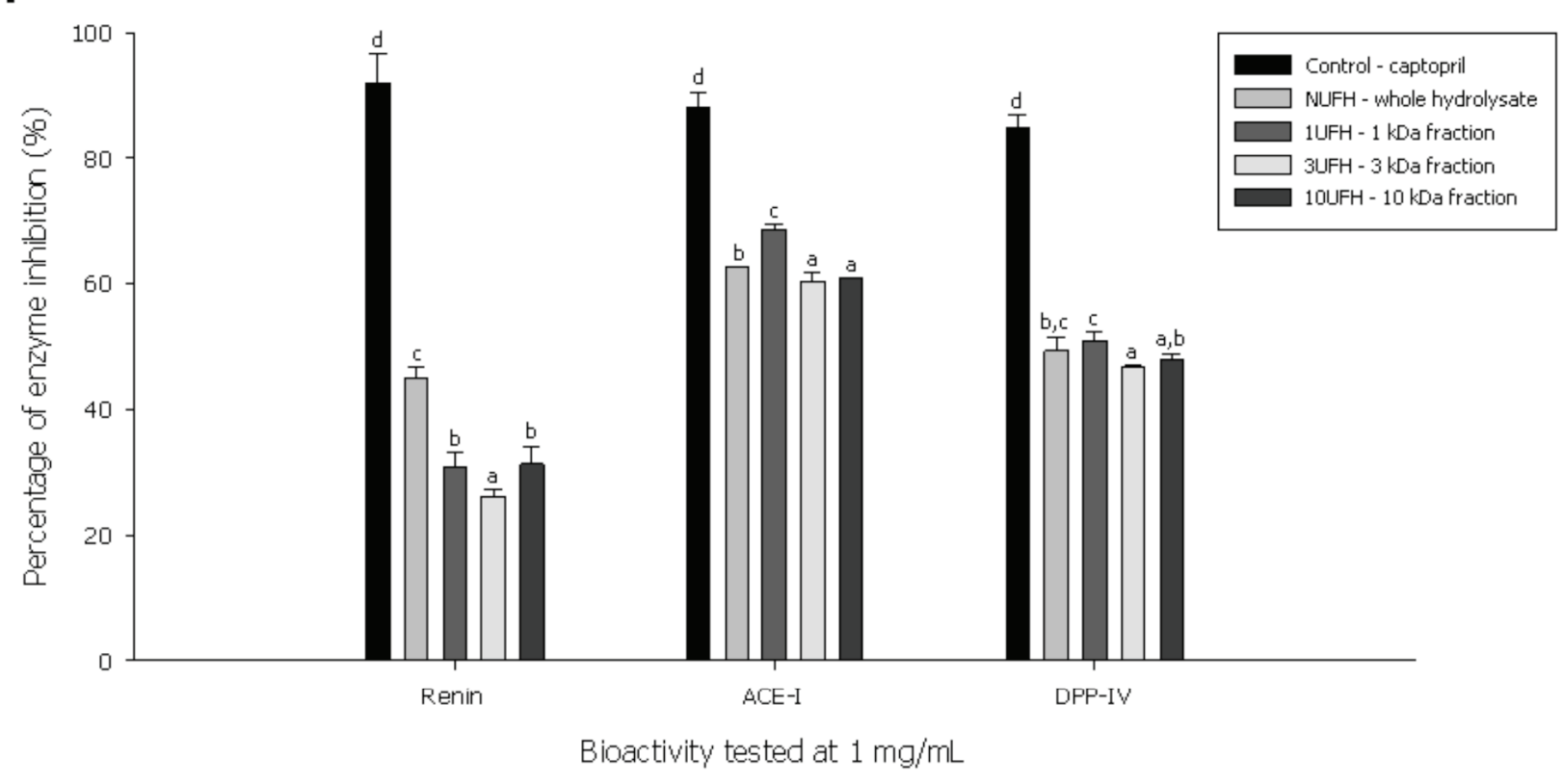


1 Table 1: peptides identified by HPLC-MS/MS predicted to be bioactive and

2 allergenic in silico

3

\begin{tabular}{|c|c|c|}
\hline Amino acid sequence & Parent protein (UniProt ID) & $\begin{array}{l}\text { PeptideRanker } \\
\text { score }^{1}\end{array}$ \\
\hline ALLAALDWLCQRLL & O77667IDHI2_BOVIN & 0.91 \\
\hline KPAMPFDLMVY & Q2UVX4|CO3_BOVIN & 0.85 \\
\hline AIDAPSNLRFL & P07589|FINC_BOVIN & 0.83 \\
\hline QPQPHPQPPPYG & P07589|FINC_BOVIN & 0.82 \\
\hline TPKFFKPAMPFDLMVY & Q2UVX4ICO3_BOVIN & 0.82 \\
\hline SFSSLKDYWSSFK & P19035|APOC3_BOVIN & 0.80 \\
\hline GVSSDLWGEKPKISYIIG & Q2UVX4ICO3_BOVIN & 0.78 \\
\hline SEGALSPGGLASLLR & P01030|CO4_BOVIN & 0.77 \\
\hline DELFQDRFFLR & P17697ICLUS_BOVIN & 0.76 \\
\hline YGAEALERMFL & P01966lHBA_BOVIN & 0.75 \\
\hline SLFDAPDFSKITG & Q95121|PEDF_BOVIN & 0.74 \\
\hline PGRPEPGSAGTWN & P02672|FIBA_BOVIN & 0.73 \\
\hline PNIIPEGDFKSFVR & P01030|CO4_BOVIN & 0.73 \\
\hline SIMDELFQDRFF & P17697|CLUS_BOVIN & 0.73 \\
\hline SSIMDELFQDRFF & P17697ICLUS_BOVIN & 0.73 \\
\hline SSIMDELFQDRFFLR & P17697|CLUS_BOVIN & 0.73 \\
\hline SDLWGEKPKISYIIG & Q2UVX4|CO3_BOVIN & 0.73 \\
\hline QEHFGKDKPDNFQLF & Q29443|TRFE_BOVIN & 0.72 \\
\hline ASSIMDELFQDRFFLR & P17697ICLUS_BOVIN & 0.71 \\
\hline SIMDELFQDRFFLR & P17697|CLUS_BOVIN & 0.71 \\
\hline PLPAPSQPIVF & Q2KIU3|HP252_BOVIN & 0.71 \\
\hline GHAAEYGAEALERMFL & P01966lHBA_BOVIN & 0.70 \\
\hline AEYGAEALERMFL & P01966|HBA_BOVIN & 0.69 \\
\hline IMDELFQDRFF & P17697|CLUS_BOVIN & 0.69 \\
\hline ESFSSLKDYWSSFK & P19035|APOC3_BOVIN & 0.69 \\
\hline EHFGKDKPDNFQLF & Q29443|TRFE_BOVIN & 0.69 \\
\hline KDKPDNFQLFQ & Q29443|TRFE_BOVIN & 0.69 \\
\hline ASSIMDELFQDRFF & P17697|CLUS_BOVIN & 0.68 \\
\hline HFGKDKPDNFQLFQ & Q29443|TRFE_BOVIN & 0.68 \\
\hline FPSRGNLDDFFH & P02672|FIBA_BOVIN & 0.67 \\
\hline HNCCILDERFG & P12799|FIBG_BOVIN & 0.66 \\
\hline IMDELFQDRFFLR & P17697|CLUS_BOVIN & 0.66 \\
\hline LLPVLESLKVSILAAIDEASKKLNAQ & P15497|APOA1_BOVIN & 0.63 \\
\hline AQEHFGKDKPDNFQLFQ & Q29443|TRFE_BOVIN & 0.63 \\
\hline DADFDWHHTFPS & P02672|FIBA_BOVIN & 0.62 \\
\hline SNTDFAFSLYKQL & A6QPQ2ISPA38_BOVIN & 0.62 \\
\hline CVPCADQSSFPK & Q29443|TRFE_BOVIN & 0.62 \\
\hline ISPFHEFAEVVF & O46375|TTHY_BOVIN & 0.61 \\
\hline EEFREGARQKVQELQDKLSPLAQELRDRAR & P15497|APOA1_BOVIN & 0.61 \\
\hline
\end{tabular}




\begin{tabular}{|c|c|c|}
\hline SSNTDFAFSLYKQLAL & A6QPQ2ISPA38_BOVIN & 0.60 \\
\hline SNTDFAFSLYK & A6QPQ2ISPA38_BOVIN & 0.59 \\
\hline HAAEYGAEALERMFL & P01966lHBA_BOVIN & 0.59 \\
\hline QQMIFEEHGFR & P07589|FINC_BOVIN & 0.59 \\
\hline EHFGKDKPDNFQLFQ & Q29443ITRFE_BOVIN & 0.59 \\
\hline SSNTDFAFSLYK & A6QPQ2ISPA38_BOVIN & 0.58 \\
\hline AIDAPSNLRFLAT & P07589|FINC_BOVIN & 0.58 \\
\hline GKEDVIWELLNHAQEHFGK & Q29443|TRFE_BOVIN & 0.58 \\
\hline SNTDFAFSLYKQLALK & A6QPQ2ISPA38_BOVIN & 0.57 \\
\hline SSNTDFAFSLYKQLALK & A6QPQ2ISPA38_BOVIN & 0.57 \\
\hline KLLDNWDTLAL & P15497|APOA1_BOVIN & 0.57 \\
\hline NHAQEHFGKDKPDNFQLF & Q29443|TRFE_BOVIN & 0.56 \\
\hline KGQVLKDLKELVF & Q7SIH1IA2MG_BOVIN & 0.56 \\
\hline NLDDFFHRDKDDFFTR & P02672|FIBA_BOVIN & 0.55 \\
\hline ASEQLKALGEKAKPVL & P15497|APOA1_BOVIN & 0.55 \\
\hline EDLRQGLLPVLESLKVSILAAIDEASKKLNAQ & P15497|APOA1_BOVIN & 0.55 \\
\hline SPNFMENVAEKALQQYRRKSQEE & P17697|CLUS_BOVIN & 0.55 \\
\hline ASSNTDFAFSLYKQLAL & A6QPQ2ISPA38_BOVIN & 0.54 \\
\hline SNTDFAFSLYKQLAL & A6QPQ2ISPA38_BOVIN & 0.54 \\
\hline AGTDLLNFLSR & P81644|APOA2_BOVIN & 0.54 \\
\hline LPAQEEMPVPLG & Q32PJ2IAPOA4_BOVIN & 0.54 \\
\hline EKFPGIPFPLDAAVE & Q3SZV7IHEMO_BOVIN & 0.54 \\
\hline PPSGDFLTEGGGVR & P02672|FIBA_BOVIN & 0.53 \\
\hline GEKAKPVLEDLRQGLLPVLE & P15497|APOA1_BOVIN & 0.53 \\
\hline GKQLNLKLLDNWDTLAS & P15497|APOA1_BOVIN & 0.53 \\
\hline WQQDDPQSSWDRVK & P15497|APOA1_BOVIN & 0.53 \\
\hline HAQEHFGKDKPDNFQLF & Q29443|TRFE_BOVIN & 0.53 \\
\hline HAQEHFGKDKPDNFQLFQ & Q29443|TRFE_BOVIN & 0.53 \\
\hline WGETQGTFGEGLLK & P06868|PLMN_BOVIN & 0.52 \\
\hline AGTDLLNFLSSFIDPKKQPAT & P81644IAPOA2_BOVIN & 0.52 \\
\hline TDLLNFLSSFIDPKKQPAT & P81644|APOA2_BOVIN & 0.52 \\
\hline GKLNHQLEGLAF & Q32PJ2IAPOA4_BOVIN & 0.52 \\
\hline DDPQSSWDRVKDFA & P15497|APOA1_BOVIN & 0.51 \\
\hline KNPSSWPVSLQ & Q08DV9|T131L_BOVIN & 0.51 \\
\hline SNTDFAFSLYKQLA & A6QPQ2ISPA38_BOVIN & 0.50 \\
\hline SADGFLKIPSK & Q29443ITRFE_BOVIN & 0.50 \\
\hline GVSSDLWGEKPKISY & Q2UVX4|CO3_BOVIN & 0.50 \\
\hline
\end{tabular}


5 Table 2: peptides identified by HPLC-MS/MS predicted to be non-allergenic in silico.

\begin{tabular}{|c|c|c|c|}
\hline Amino acid sequence & Parent protein (UniProt ID) & Globulin fraction & PeptideRanker score $^{1}$ \\
\hline NIRPSSPDWGTF & P02672|FIBA_BOVIN & FI & 0.69 \\
\hline NIRPSSPDWGTFR & P02672|FIBA_BOVIN & FI & 0.67 \\
\hline LNGVQPSRADALVG & Q2UVX4ICO3_BOVIN & FI and FII & 0.34 \\
\hline TKKDNIPEGRQATR & Q2UVX4|CO3_BOVIN & FI and FII & 0.10 \\
\hline EDNTIHWTRPQ & Q7SIH1IA2MG_BOVIN & FI and FII & 0.19 \\
\hline HGRKDTIIKPLL & Q7SIH1IA2MG_BOVIN & FI and FII & 0.42 \\
\hline STKSPDLEPVLR & P01044|KNG1_BOVIN & FII & 0.28 \\
\hline TKSPDLEPVLR & P01044-2|KNG1_BOVIN & FII & 0.29 \\
\hline SDLHAHKLRVDPVN & P01966IHBA_BOVIN & FII & 0.29 \\
\hline MSTITGPVPREFK & P02672|FIBA_BOVIN & FII & 0.17 \\
\hline TWNPGRPEPGSA & P02672|FIBA_BOVIN & FII & 0.27 \\
\hline TWNPGRPEPGSAGTWN & P02672|FIBA_BOVIN & FII & 0.55 \\
\hline SPYVPWIEETMRRN & P06868IPLMN_BOVIN & FII & 0.66 \\
\hline KALGGEDVRVT & P12763|FETUA_BOVIN & FII & 0.13 \\
\hline AHVETLRQQLAPYSDDLR & P15497|APOA1_BOVIN & FII & 0.13 \\
\hline APYSDDLRQRLTA & P15497|APOA1_BOVIN & FII & 0.35 \\
\hline APYSDDLRQRLTAG & P15497|APOA1_BOVIN & FII & 0.36 \\
\hline EKAKPVLEDLRQGLMPVL & P15497|APOA1_BOVIN & FII & 0.54 \\
\hline KQLNLKLLDNWDTLASTLSKVR & P15497|APOA1_BOVIN & FII & 0.11 \\
\hline LSKVREQLGPVT & P15497|APOA1_BOVIN & FII & 0.13 \\
\hline QLNLKLLDNWDTLASTLSKVR & P15497|APOA1_BOVIN & FII & 0.23 \\
\hline STLSKVREQLGPVT & P15497|APOA1_BOVIN & FII & 0.10 \\
\hline STLSKVREQLGPVTQ & P15497|APOA1_BOVIN & FII & 0.08 \\
\hline TLSKVREQLGPVT & P15497|APOA1_BOVIN & FII & 0.09 \\
\hline
\end{tabular}




\begin{tabular}{|c|c|c|c|}
\hline TLSKVREQLGPVTK & P15497|APOA1_BOVIN & FII & 0.08 \\
\hline TLSKVREQLGPVTL & P15497|APOA1_BOVIN & FII & 0.12 \\
\hline TLSKVREQLGPVTQ & P15497|APOA1_BOVIN & FII & 0.07 \\
\hline TLSKVREQLGPVTR & P15497|APOA1_BOVIN & FII & 0.10 \\
\hline QARDWMTESFSSLK & P19035IAPOC3_BOVIN & FII & 0.37 \\
\hline QQARDWMTESF & P19035|APOC3_BOVIN & FII & 0.49 \\
\hline QQARDWMTESFS & P19035IAPOC3_BOVIN & FII & 0.29 \\
\hline DRTAGWNIPMG & P24627ITRFL_BOVIN & FII & 0.65 \\
\hline RTAGWNIPMGL & P24627ITRFL_BOVIN & FII & 0.76 \\
\hline VDRTAGWNIPMG & P24627ITRFL_BOVIN & FII & 0.53 \\
\hline EVFSDRADLSGITKEQPLKVS & P34955IA1AT_BOVIN & FII & 0.06 \\
\hline LSGITKEQPLKVS & P34955IA1AT_BOVIN & FII & 0.12 \\
\hline SDRADLSGITKEQPLK & P34955|A1AT_BOVIN & FII & 0.29 \\
\hline STLQTQDRKIVK & P81187ICFAB_BOVIN & FII & 0.08 \\
\hline LDDYLPLEMVGPRKTF & Q0VCM5IITIH1_BOVIN & FII & 0.65 \\
\hline YPREAVSDLTQ & Q0VCM5IITIH1_BOVIN & FII & 0.09 \\
\hline AHLDRGSPPPAR & Q29437|AOCX_BOVIN & FII & 0.44 \\
\hline AVDRTAGWNIPMG & Q29443ITRFE_BOVIN & FII & 0.61 \\
\hline HTAVDRTAGWNIPMG & Q29443ITRFE_BOVIN & FII & 0.40 \\
\hline KELPDPQESIQRAAA & Q29443ITRFE_BOVIN & FII & 0.16 \\
\hline RSAGWNIPMGK & Q29443ITRFE_BOVIN & FII & 0.84 \\
\hline RTVGGKEDVIWELL & Q29443ITRFE_BOVIN & FII & 0.24 \\
\hline LMRDKSSVLEKHQVS & Q2KITOIHP20_BOVIN & FII & 0.07 \\
\hline SGMLTLPLHVGEKVW & Q2KIT0|HP20_BOVIN & FII & 0.44 \\
\hline KMNDPLPAPSQPIVF & Q2KIU3|HP252_BOVIN & FII & 0.57 \\
\hline MNDPLPAPSQPIVF & Q2KIU3IHP252_BOVIN & FII & 0.59 \\
\hline
\end{tabular}




\begin{tabular}{|c|c|c|c|}
\hline SSVLELEKGDRVW & Q2KIX7IHP251_BOVIN & FII & 0.32 \\
\hline SVLELEKGDRVW & Q2KIX7IHP251_BOVIN & FII & 0.23 \\
\hline AHEHRFPLGPVT & Q2KJF1IA1BG_BOVIN & FII & 0.43 \\
\hline ALTPGRDAVLR & Q2KJF1IA1BG_BOVIN & FII & 0.26 \\
\hline ESPAHEHRFPLGPVT & Q2KJF1IA1BG_BOVIN & FII & 0.50 \\
\hline ESPAHEHRFPLGPVTS & Q2KJF1IA1BG_BOVIN & FII & 0.32 \\
\hline LESPAHEHRFPLGPVT & Q2KJF1IA1BG_BOVIN & FII & 0.39 \\
\hline LESPAHEHRFPLGPVTS & Q2KJF1IA1BG_BOVIN & FII & 0.25 \\
\hline LTVDRESAKVL & Q2KJF1IA1BG_BOVIN & FII & 0.07 \\
\hline RGAEEQLVPRAS & Q2KJF1IA1BG_BOVIN & FII & 0.11 \\
\hline SPAHEHRFPLGPVT & Q2KJF1IA1BG_BOVIN & FII & 0.59 \\
\hline SPAHEHRFPLGPVTS & Q2KJF1IA1BG_BOVIN & FII & 0.38 \\
\hline GVQPSRADALVG & Q2UVX4ICO3_BOVIN & FII & 0.35 \\
\hline HSRDGALELAR & Q2UVX4|CO3_BOVIN & FII & 0.24 \\
\hline KDNIPEGRQATRTM & Q2UVX4ICO3_BOVIN & FII & 0.28 \\
\hline LSDQVPDTESETKIL & Q2UVX4ICO3_BOVIN & FII & 0.18 \\
\hline LSDQVPDTESETKILLQ & Q2UVX4ICO3_BOVIN & FII & 0.14 \\
\hline MPFDLMVYVTNPDGSPAR & Q2UVX4|CO3_BOVIN & FII & 0.19 \\
\hline NGVQPSRADALVG & Q2UVX4|CO3_BOVIN & FII & 0.32 \\
\hline NPDGSPARHIPVVT & Q2UVX4|CO3_BOVIN & FII & 0.44 \\
\hline QNKRDPLTITVR & Q2UVX4|CO3_BOVIN & FII & 0.23 \\
\hline SINTQNKRDPLTITVR & Q2UVX4|CO3_BOVIN & FII & 0.17 \\
\hline SMITPNILRLE & Q2UVX4|CO3_BOVIN & FII & 0.29 \\
\hline TKKDNIPEGRQATRTM & Q2UVX4|CO3_BOVIN & FII & 0.18 \\
\hline QLDTLRQKLGPLAGDVEDHLSFLEKDLRDKVS & Q32PJ2|APOA4_BOVIN & FII & 0.36 \\
\hline RQLTPYAERMEKVM & Q32PJ2|APOA4_BOVIN & FII & 0.26 \\
\hline
\end{tabular}




\begin{tabular}{|c|c|c|c|}
\hline GPKPALPAGTEDTAKEDAANRKLAK & Q3SX14|GELS_BOVIN & FII & 0.36 \\
\hline ERWKDAPSPVD & Q3SZV7IHEMO_BOVIN & FII & 0.21 \\
\hline DVLWGPLDTADDSKRTLKVQ & Q3T052IITIH4_BOVIN & FII & 0.16 \\
\hline GPLDTADDSKRTLKVQ & Q3T052IITIH4_BOVIN & FII & 0.14 \\
\hline IHASPEHVVMTR & Q3T052IITIH4_BOVIN & FII & 0.32 \\
\hline KMALENGGLAR & Q3T052IITIH4_BOVIN & FII & 0.25 \\
\hline VARGESAGLVR & Q3T052IITIH4_BOVIN & FII & 0.15 \\
\hline AATDTAADAHDPARPGAKVSENL & Q7SIH1IA2MG_BOVIN & FII & 0.44 \\
\hline ADAHDPARPGAKVS & Q7SIH1IA2MG_BOVIN & FII & 0.28 \\
\hline AHDPARPGAKVS & Q7SIH1IA2MG_BOVIN & FII & 0.30 \\
\hline DAHDPARPGAKVS & Q7SIH1IA2MG_BOVIN & FII & 0.29 \\
\hline DTAADAHDPARPGAKVS & Q7SIH1IA2MG_BOVIN & FII & 0.15 \\
\hline EDNTIHWTRPQKPRLV & Q7SIH1IA2MG_BOVIN & FII & 0.28 \\
\hline FTLPRSPTSQEVMF & Q7SIH1IA2MG_BOVIN & FII & 0.36 \\
\hline HFPPAAATDTAADAHDPARPGAKVS & Q7SIH1IA2MG_BOVIN & FII & 0.25 \\
\hline KLPPNVVEESAR & Q7SIH1IA2MG_BOVIN & FII & 0.16 \\
\hline KLPPNVVEESARAS & Q7SIH1IA2MG_BOVIN & FII & 0.19 \\
\hline LPPNVVEESARAS & Q7SIH1IA2MG_BOVIN & FII & 0.16 \\
\hline LSFVTVDSNLRRGIPFTG & Q7SIH1IA2MG_BOVIN & FII & 0.28 \\
\hline QPAPNPEDLKRAT & Q7SIH1IA2MG_BOVIN & FII & 0.56 \\
\hline QPAPNPEDLKRATSIVK & Q7SIH1IA2MG_BOVIN & FII & 0.55 \\
\hline RLLIYAILPDGEVVG & Q7SIH1IA2MG_BOVIN & FII & 0.13 \\
\hline TAADAHDPARPGAKVS & Q7SIH1IA2MG_BOVIN & FII & 0.16 \\
\hline TDTAADAHDPARPGAKVS & Q7SIH1IA2MG_BOVIN & FII & 0.11 \\
\hline
\end{tabular}


References

Álvarez, C., Bances, M., Rendueles, M., \& Díaz, M. (2009). Functional properties of isolated porcine blood proteins. International Journal of Food Science and Technology, 44(4), 807-814.

Bah, C. S. F., Bekhit, A. E.-D. A., Carne, A., \& McConnell, M. A. (2013). Slaughterhouse Blood: An Emerging Source of Bioactive Compounds. Comprehensive Reviews in Food Science and Food Safety, 12(3), 314-331. doi: 10.1111/1541-4337.12013

Burks, A. W., Tang, M., Sicherer, S., Muraro, A., Eigenmann, P. A., Ebisawa, M., . . . Sampson, H. A. (2012). ICON: Food allergy. Journal of Allergy and Clinical Immunology, 129(4), 906-920.

Christer, H., Andersson, S., Arpaia, D., Casacuberta, J., Davies, H., Jardin, P., \& Flachowsky, G. (2010). Scientific Opinion on the assessment of allergenicity of GM plants and microorganisms and derived food and feed. EFSA J, 8(7), 1700 .

Chruszcz, M., Mikolajczak, K., Mank, N., Majorek, K. A., Porebski, P. J., \& Minor, W. (2013). Serum albumins-Unusual allergens. Biochimica et Biophysica Acta (BBA) - General Subjects, 1830(12), 5375-5381.

Commins, S. P., \& Platts-Mills, T. A. (2013). Tick bites and red meat allergy. Current opinion in allergy and clinical immunology, 13(4), 354.

Dent, M. P., O’Hagan, S., Braun, W. H., Schaetti, P., Marburger, A., \& Vogel, O. (2007). A 90-day subchronic toxicity study and reproductive toxicity studies on ACE-inhibiting lactotripeptide. Food and Chemical Toxicology, 45(8), 1468-1477. doi: http://dx.doi.org/10.1016/j.fct.2007.02.006

Dicker, D. (2011). DPP-4 Inhibitors Impact on glycemic control and cardiovascular risk factors. Diabetes care, 34(2), S276-S278.

Dimitrov, I., Bangov, I., Flower, D., \& Doytchinova, I. (2014). AllerTOP v.2-a server for in silico prediction of allergens. Journal of Molecular Modeling, 20(6), 1-6.

Fiocchi, A., Restani, P., \& Riva, E. (2000). Beef allergy in children. Nutrition, 16(6), 454-457.

Fuentes, M. M., Palacios, R., Garcés, M. M., Caballero, M. L., \& Moneo, I. (2004). Isolation and characterization of a heat-resistant beef allergen: myoglobin. Allergy, 59(3), 327-331.

Gasteiger, E., Gattiker, A., Hoogland, C., Ivanyi, I., Appel, R. D., \& Bairoch, A. (2003). ExPASy: the proteomics server for in-depth protein knowledge and analysis. Nucleic Acids Research, 31(13), 3784-3788.

Gupta, S., Kapoor, P., Chaudhary, K., Gautam, A., Kumar, R., \& Raghava, G. P. S. (2013). In Silico Approach for Predicting Toxicity of Peptides and Proteins. PLoS ONE, 8(9).

Hamsten, C., Starkhammar, M., Tran, T., Johansson, M., Bengtsson, U., Ahlen, G., . . - Hage, M. (2013). Identification of galactose- $\alpha-1$, 3-galactose in the 
gastrointestinal tract of the tick Ixodes ricinus; possible relationship with red meat allergy. Allergy, 68(4), 549-552.

He, R., Alashi, A., Malomo, S. A., Girgih, A. T., Chao, D., Ju, X., \& Aluko, R. E. (2013). Antihypertensive and free radical scavenging properties of enzymatic rapeseed protein hydrolysates. Food Chemistry, 141(1), 153-159.

Hemmer, W., Mayer, D., \& Jarisch, R. (2011). Meat allergy. [Review]. Allergologie, 34(8), 373-387.

Høst, A., \& Halken, S. (2004). Hypoallergenic formulas-when, to whom and how long: after more than 15 years we know the right indication! Allergy, 59(s78), 45-52.

Hyun, C. K., \& Shin, H. K. (2000). Utilization of bovine blood plasma proteins for the production of angiotensin I converting enzyme inhibitory peptides. Process Biochemistry, 36(1-2), 65-71.

Irvine, G. B. (2003). High-performance size-exclusion chromatography of peptides. Journal of Biochemical and Biophysical Methods, 56(1-3), 233-242.

Jamasbi, E., Batinovic, S., Sharples, R., Sani, M.-A., Robins-Browne, R., Wade, J., . . . Hossain, M. (2014). Melittin peptides exhibit different activity on different cells and model membranes. Amino Acids, 46(12), 2759-2766.

Jamdar, S. N., Rajalakshmi, V., Pednekar, M. D., Juan, F., Yardi, V., \& Sharma, A. (2010). Influence of degree of hydrolysis on functional properties, antioxidant activity and ACE inhibitory activity of peanut protein hydrolysate. Food Chemistry, 121(1), 178-184.

Juillerat-Jeanneret, L. (2014). Dipeptidyl peptidase IV and its inhibitors: Therapeutics for type 2 diabetes and what else? Journal of Medicinal Chemistry, 57(6), 2197-2212. doi: 10.1021/jm400658e

Kazatsky, A. M., \& Wood, R. A. (2016). Classification of Food Allergens and CrossReactivity. Current Allergy and Asthma Reports, 16(3), 1-7.

Kim, K.-B.-W.-R., Lee, S.-Y., Song, E.-J., Kim, K.-E., \& Ahn, D.-H. (2011). Effect of heat and autoclave on allergenicity of porcine serum albumin. Food Science and Biotechnology, 20(2), 455-459.

Kolar, K. (1992). Gravimetric determination of moisture and ash in meat and meat products: NMKL interlaboratory study. Journal of AOAC International (USA). 75(6), 1016-1022.

Korhonen, H., \& Pihlanto, A. (2006). Bioactive peptides: Production and functionality. International Dairy Journal, 16(9), 945-960.

Lafarga, T., Aluko, R. E., Rai, D. K., O'Connor, P., \& Hayes, M. (2016). Identification of bioactive peptides from a papain hydrolysate of bovine serum albumin and assessment of an antihypertensive effect in spontaneously hypertensive rats. Food Research International, 81, 91-99.

Lafarga, T., Gallagher, E., Aluko, R. E., Auty, M. A. E., \& Hayes, M. (2016). Addition of an Enzymatic Hydrolysate of Bovine Globulins to Bread and Determination of Hypotensive Effects in Spontaneously Hypertensive Rats. Journal of Agricultural and Food Chemistry, 64(8), 1741-1750. 
Lafarga, T., \& Hayes, M. (2014). Bioactive peptides from meat muscle and byproducts: Generation, functionality and application as functional ingredients. Meat Science, 98(2), 227-239.

Lafarga, T., Rai, D. K., O'Connor, P., \& Hayes, M. (2015). A Bovine FibrinogenEnriched Fraction as a Source of Peptides with in Vitro Renin and Angiotensin-I-Converting Enzyme Inhibitory Activities. Journal of Agricultural and Food Chemistry, 63(39), 8676-8684.

Larché, M. (2007). Immunotherapy with allergen peptides. Allergy, Asthma and Clinical Immunology, 3(2), 53.

Li-Chan, E. C. Y., Hunag, S. L., Jao, C. L., Ho, K. P., \& Hsu, K. C. (2012). Peptides derived from Atlantic salmon skin gelatin as dipeptidyl-peptidase IV inhibitors. Journal of Agricultural and Food Chemistry, 60(4), 973-978.

Li, H., \& Aluko, R. E. (2010). Identification and inhibitory properties of multifunctional peptides from pea protein hydrolysate. Journal of Agricultural and Food Chemistry, 58(21), 11471-11476.

Marques, A., Lourenço, H. M., Nunes, M. L., Roseiro, C., Santos, C., Barranco, A., . . . Cencic, A. (2011). New tools to assess toxicity, bioaccessibility and uptake of chemical contaminants in meat and seafood. Food research international, 44(2), 510-522.

Martelli, A., De Chiara, A., Corvo, M., Restani, P., \& Fiocchi, A. (2002). Beef allergy in children with cow's milk allergy; cow's milk allergy in children with beef allergy. Annals of Allergy, Asthma \& Immunology, 89(6), 38-43.

Mittag, D., Batori, V., Neudecker, P., Wiche, R., Friis, E. P., Ballmer-Weber, B. K., . . . Roggen, E. L. (2006). A novel approach for investigation of specific and cross-reactive IgE epitopes on Bet $\mathrm{v} 1$ and homologous food allergens in individual patients. Molecular immunology, 43(3), 268-278.

Mooney, C., Haslam, N. J., Pollastri, G., \& Shields, D. C. (2012). Towards the Improved Discovery and Design of Functional Peptides: Common Features of Diverse Classes Permit Generalized Prediction of Bioactivity. PLoS ONE, 7(10), e45012.

Moure, F., Rendueles, M., \& Diaz, M. (2003). Coupling process for plasma protein fractionation using ethanol precipitation and ion exchange chromatography. Meat Science, 64(4), 391-398.

Mundi, S., \& Aluko, R. E. (2014). Inhibitory Properties of Kidney Bean Protein Hydrolysate and its Membrane Fractions Against Renin, Angiotensin Converting Enzyme, and Free Radicals. Austin J Nutri Food Sci, 2(1), 11.

Panda, R., Tetteh, A. O., Pramod, S. N., \& Goodman, R. E. (2015). Enzymatic Hydrolysis Does Not Reduce the Biological Reactivity of Soybean Proteins for All Allergic Subjects. Journal of Agricultural and Food Chemistry, 63(43), 9629-9639.

Parés, D., Toldrà, M., Saguer, E., \& Carretero, C. (2014). Scale-up of the process to obtain functional ingredients based in plasma protein concentrates from porcine blood. Meat Science, 96(1), 304-310. 
Ponstein-Simarro Doorten, A. Y., vd Wiel, J. A. G., \& Jonker, D. (2009). Safety evaluation of an IPP tripeptide-containing milk protein hydrolysate. Food and Chemical Toxicology, 47(1), 55-61.

Purello-d'ambrosio, F., Gangemi, S., La Rosa, G., Merendino, R. A., \& Tomasello, F. (2000). Allergy to gelatin. Allergy, 55(4), 414-415.

Rahaman, T., Vasiljevic, T., \& Ramchandran, L. (2016). Effect of processing on conformational changes of food proteins related to allergenicity. Trends in Food Science \& Technology, 49, 24-34.

Ribatti, D. (2016). The discovery of immunoglobulin E. Immunology Letters, 171, 14.

Sabadin, I. S., Villas-Boas, M. B., de Lima Zollner, R., \& Netto, F. M. (2012). Effect of combined treatment of hydrolysis and polymerization with transglutaminase on $\beta$-lactoglobulin antigenicity. European Food Research and Technology, 235(5), 801-809.

Saha, S., \& Raghava, G. (2006). AlgPred: prediction of allergenic proteins and mapping of IgE epitopes. Nucleic acids research, 34(2), W202-W209.

Schaafsma, G. (2009). Safety of protein hydrolysates, fractions thereof and bioactive peptides in human nutrition. Eur J Clin Nutr, 63(10), 1161-1168.

Silveira, S. T., Martínez-Maqueda, D., Recio, I., \& Hernández-Ledesma, B. (2013). Dipeptidyl peptidase-IV inhibitory peptides generated by tryptic hydrolysis of a whey protein concentrate rich in $\beta$-lactoglobulin. Food Chemistry, 141(2), 1072-1077.

Stone, K. D., Prussin, C., \& Metcalfe, D. D. (2010). IgE, mast cells, basophils, and eosinophils. Journal of Allergy and Clinical Immunology, 125(2), S73-S80.

Tarlo, S., Shaikh, W., Bell, B., Cuff, M., Davies, G., Dolovich, J., \& Hargreave, F. (1978). Papain-induced allergic reactions. Clinical \& Experimental Allergy, $8(3), 207-215$.

Turnbull, J. L., Adams, H. N., \& Gorard, D. A. (2015). Review article: the diagnosis and management of food allergy and food intolerances. Alimentary Pharmacology \& Therapeutics, 41(1), 3-25.

Udenigwe, C. C., Lin, Y.-S., Hou, W.-C., \& Aluko, R. E. (2009). Kinetics of the inhibition of renin and angiotensin I-converting enzyme by flaxseed protein hydrolysate fractions. Journal of Functional Foods, 1(2), 199-207.

Van Nunen, S. A., O'Connor, K. S., Clarke, L. R., Boyle, R. X., \& Fernando, S. L. (2009). An association between tick bite reactions and red meat allergy in humans. The Medical Journal of Australia, 190(9), 510-511.

Velarde-Salcedo, A. J., Barrera-Pacheco, A., Lara-González, S., Montero-Morán, G. M., Díaz-Gois, A., González de Mejia, E., \& Barba de la Rosa, A. P. (2013). In vitro inhibition of dipeptidyl peptidase IV by peptides derived from the hydrolysis of amaranth (Amaranthus hypochondriacus L.) proteins. Food Chemistry, 136(2), 758-764.

Wang, W., \& De Mejia, E. G. (2005). A New Frontier in Soy Bioactive Peptides that May Prevent Age-related Chronic Diseases. Comprehensive Reviews in Food Science and Food Safety, 4(4), 63-78. 
Wu, J., Aluko, R. E., \& Nakai, S. (2006). Structural requirements of angiotensin Iconverting enzyme inhibitory peptides: Quantitative structure-activity relationship study of Di- and tripeptides. Journal of Agricultural and Food Chemistry, 54(3), 732-738.

Yilmaz, I., Kaya, E., Sinirlioglu, Z. A., Bayram, R., Surmen, M. G., \& Colakoglu, S. (2014). Clinical importance of toxin concentration in Amanita verna mushroom. Toxicon, 87, 68-75. 